\title{
The association of oxidative stress with serum irisin and betatrophin in pregnant women with gestational diabetes mellitus
}

\section{ABSTRACT}

Background. Irisin and betatrophin are polypeptide hormones implicated in glucose metabolism and insulin resistance (IR). Gestational diabetes mellitus (GDM) is accompanied by oxidative stress (OS) and the association between circulating irisin and betatrophin levels and GDM is controversial. The present study aimed to investigate the association of second-trimester irisin, betatrophin concentrations and their correlations between serum OS markers in GDM patients.

Methods. The study included 45 GDM patients and 45-age matched pregnant women as controls. Serum fasting glucose, HOMA-IR, ischemia modified albumin (IMA), total oxidative stress (TOS), total antioxidant status (TAS), oxidative stress index (OSI), irisin and betatrophin were measured.

Results. Serum irisin levels were decreased and TOS and OSI levels were found to be increased in the patient group. No significant difference was found with respect to serum betatrophin and IMA levels between study groups. A correlation analysis revealed no correlation between serum irisin and other assessed variables.

Conclusions. Gestational diabetes mellitus is an os condition in addition to being a metabolic disease.

Address for correspondence:

Fatma Beyazit

Canakkale Onsekiz Mart University

Department of Obstetrics and Gynecology

Kepez, Canakkale, Turkey

Phone: +902862171098

Fax: +902862133622

e-mail: fatmabeyazit@yahoo.com

Clinical Diabetology 2020, 9; 5: 328-334

DOI: $10.5603 /$ DK.2020.0039

Received: 09.05.2020
Although not correlated with OS, irisin but not betatrophin may be a useful biomarker to predict GDM. (Clin Diabet 2020; 9; 5: 328-334)

Key words: irisin, betatrophin, oxidative stress, gestational diabetes mellitus

\section{Introduction}

Gestational diabetes mellitus (GDM) defined as an impaired glucose tolerance of varying severity with onset or first recognition during pregnancy that may result in increased negative maternal and fetal outcomes [1]. It affects about nearly $15-20 \%$ of all pregnancies. Despite the increased rates of GDM detection with negative perinatal outcomes, the pathophysiologic mechanisms underlying GDM are still not fully understood. Recent studies suggest that oxidative stress (OS) and several polypeptide hormones apart from insulin could affect glucose metabolism and low-grade inflammation [2-4].

Irisin is a fragment of a cell membrane protein that is cleaved from the fibronectin type III domaincontaining 5 (FNDC5) in skeletal muscles. Being a novel adipokine and myokine, it involves in exercise, total body energy expenditure and thermogenesis and contributes to the regulation of glucose and lipid metabolism in skeletal muscle and adipose tissue by improving insulin sensitivity [5]. Lower levels of irisin in DM patients supports the idea that irisin could be a protective response of organism to early glucose impairments by taking a crucial role in pancreatic $\beta$-cell function. Nevertheless, to date, there are only a paucity of data exists on irisin and human pregnancy including GDM $[6,7]$. Since irisin could potentially counteract 
impaired glucose control seen in GDM by improving $\beta$-cell function, our rationale was to investigate this polypeptide hormone and its potential associations with other metabolic markers and OS in GDM.

Betatrophin (also known as lipasin, Hepatocellular Carcinoma-Associated Gene TD26 or ANGPTL8) is a stress-response protein and has been introduced as a novel adipokine/hepatokine that down-regulates expression of adipocyte triglyceride lipase, improves glucose tolerance and promotes pancreatic $\beta$-cell proliferation [8]. Unfortunately accumulating data on betatrophin regulation in humans is partly limited to patients with adult obesity, fatty liver, diabetes mellitus (DM) and peripheral artery disease [9-12]. However, regulation of betatrophin as well as its association with irisin and other markers of OS have not been elucidated yet.

Oxidative stress is a major culprit in the pathogenesis of GDM. Enhanced oxidation products such as protein carbonyl, glutathione peroxidase and paraoxonase in GDM patients and reduced antioxidant capacity suggest that OS is a key factor in the development and progression of GDM [13]. It is believed that insulin resistance (IR) and glucose tolerance are strictly linked with OS levels and this leads to subclinical inflammation and altered biochemical pathways resulting in GDM-associated negative outcomes among pregnant women [14]. OS is a feature of normal pregnancy and partially produced in the placenta, and is heightened in pathological pregnancies including GDM. Although elevated levels of OS markers such as advanced glycated end products (AGEs), nitrotyrosine, malondialdehyde (MDA), and oxidized low-density lipoproteins (Ox-LDL) have been shown to be promising biomarkers for GDM, there are still debates on other markers including ischemia modified albumin (IMA) and total oxidant status (TOS) $[2,3,15,16]$.

Since GDM is regarded as an OS-related disorder and prediabetic condition with an enormous IR and inadequate insulin compensation, we hypothesized that betatrophin levels may be increased in women with GDM and these levels may be correlated with OS markers and circulating irisin levels.

\section{Methods}

Study design

This cross-sectional study was conducted in the Obstetrics and Gynecology department of Canakkale Onsekiz Mart University (COMU) Training and Research Hospital. Ethical board approval was obtained from COMU Faculty of Medicine Ethical Committee. Informed consent was provided by all study participants.

\section{Subjects}

From the population of 352 pregnant women routinely tested for GDM with a $75 \mathrm{~g}$ 2-hour oral glucose tolerance test (OGTT) between $24^{\text {th }}$ and $28^{\text {th }}$ weeks of gestation, 45 patients with GDM and 45 women with normal glucose tolerance (NGT), matched for age, gestational age and body mass index (BMI) were recruited for this study. GDM was diagnosed according to the criteria of The International Association of Diabetes and Pregnancy Study Groups on the basis of one or more of the following threshold glucose levels: fasting $\geq 92 \mathrm{mg} / \mathrm{dL}, 1 \mathrm{~h} \geq 180 \mathrm{mg} / \mathrm{dL}$ and $2 \mathrm{~h}$ $\geq 153 \mathrm{mg} / \mathrm{dL}$ [17]. Pregnant women with conditions including obesity, multiple pregnancies, pre-existing glucose intolerance, vascular disease, having acute or chronic liver or renal disease, polycystic ovary disease, preeclampsia and acute or chronic inflammation were excluded from the current study. Maternal pregnancy characteristics including maternal age, BMI, smoking status, gestational weeks at sampling, history of spontaneous abortion, first-degree relative with diabetes and history of accompanying chronic disease were collected and recorded for each subject.

\section{Biochemical analyses}

After an overnight fasting, venous blood samples were obtained from each subject to assess study parameters on the day of OGTT screening. All samples were centrifuged within $30 \mathrm{~min}$ at $3000 \mathrm{rpm}$ for $15 \mathrm{~min}$ to separate serum. Serum specimens were aliquoted and stored for analysis at $-80^{\circ} \mathrm{C}$ until the biochemical estimation of irisin, betatrophin, TOS, TAS, and IMA. Insulin resistance was estimated by homeostasis model of assessment insulin resistance (HOMA-IR) as suggested by Matthews et al. [18] using serum glucose and insulin levels (HOMA-IR = fasting plasma insulin [mU/ $/ \mathrm{mL}] \times$ fasting plasma glucose $[\mathrm{mg} / \mathrm{dL}] / 405)$.

\section{Measurement of TOS, TAS and IMA}

Serum TAS and TOS levels were measured with spectrophotometric kits (Rel Assay Diagnostics, Gaziantep, Turkey) according to the method previously described by Jansen and Ruskovska [19]. The results for TAS and TOS are expressed as mmol Trolox equivalent/L and $\mu \mathrm{mol} \mathrm{H} 2 \mathrm{O} 2$ equivalent/L, respectively. IMA measurements were performed according to the colorimetric method described by Bar-Or et al. [20]. Results were reported in absorbance ( $A B S U$ ) units.

\section{Determination of the OSI and IMAR}

The ratio percentage of TOS to TAS was used to calculate the OSI. Specifically, OSI (arbitrary unit) 
Table 1. Demographic and laboratory characteristics of gestational diabetes mellitus (GDM) patients and controls

\begin{tabular}{|c|c|c|c|}
\hline & GDM patients $(n=45)$ & Controls $(n=45)$ & $\mathbf{P}$ \\
\hline Maternal age (years) & $30.75 \pm 4.99$ & $28.17 \pm 5.15$ & 0.181 \\
\hline Gravidity [median (min-max)] & $2(1-5)$ & $2(1-5)$ & 0.122 \\
\hline $\mathrm{BMI}$ at the time of OGTT $\left[\mathrm{kg} / \mathrm{m}^{2}\right]$ & $25.9 \pm 3.9$ & $24.0 \pm 4.6$ & 0.056 \\
\hline Fasting blood glucose $[\mathrm{mg} / \mathrm{dL}]$ & $94.48 \pm 21.63$ & $79.51 \pm 6.76$ & 0.001 \\
\hline OGTT-1 ${ }^{\text {st }}$ hour $[\mathrm{mg} / \mathrm{dL}]$ & $174.65 \pm 32.47$ & $128.35 \pm 26.52$ & 0.001 \\
\hline OGTT-2 ${ }^{\text {nd }}$ hour $[\mathrm{mg} / \mathrm{dL}]$ & $141.78 \pm 30.53$ & $106.17 \pm 21.77$ & 0.001 \\
\hline Insulin $[\mu \mathrm{IU} / \mathrm{mL}]$ & $14.35 \pm 8.74$ & $10.49 \pm 7.00$ & 0.023 \\
\hline HOMA-IR (\%) & $3.36 \pm 2.19$ & $2.07 \pm 1.38$ & 0.001 \\
\hline $\mathrm{TSH}[\mu \mathrm{IU} / \mathrm{mL}]$ & $2.40 \pm 1.65$ & $2.44 \pm 1.17$ & 0.896 \\
\hline Total cholesterol [mg/dL] & $217.9 \pm 50.6$ & $233.4 \pm 37.5$ & 0.102 \\
\hline Triglyceride [mg/dL] & $223.0 \pm 85.5$ & $202.1 \pm 64.6$ & 0.195 \\
\hline Albumin $[\mathrm{g} / \mathrm{dL}]$ & $3.74 \pm 0.23$ & $3.90 \pm 0.19$ & 0.001 \\
\hline TOS $\left[\mu \mathrm{mol} \mathrm{H} \mathrm{H}_{2} \mathrm{O}_{2}\right.$ equivalent/L] & $11.72 \pm 2.48$ & $7.19 \pm 3.27$ & 0.001 \\
\hline TAS [mmol Trolox equivalent/L] & $0.71 \pm 0.30$ & $0.66 \pm 0.32$ & 0.501 \\
\hline OSI & $21.83 \pm 15.65$ & $11.88 \pm 9.32$ & 0.002 \\
\hline IMA [ABSU] & $0.44 \pm 0.08$ & $0.0047 \pm 0.05$ & 0.069 \\
\hline IMAR $[A B S U / g]$ & $0.12 \pm 0.02$ & $0.12 \pm 0.01$ & 0.595 \\
\hline Betatrophin [ng/mL] & $218.1 \pm 244.2$ & $225.2 \pm 200.7$ & 0.881 \\
\hline Irisin $[\mu \mathrm{g} / \mathrm{mL}]$ & $2.62 \pm 1.20$ & $3.41 \pm 2.22$ & 0.038 \\
\hline
\end{tabular}

$1 / 4\left[\left(T O S, \mu \mathrm{mol} \mathrm{H}_{2} \mathrm{O}_{2}\right.\right.$ equivalent/L)/(TAS, mmol Trolox equivalent/L)].

After measuring serum albumin concentration with a standard commercial kit, IMAR levels were calculated as a ratio of IMA to albumin, and the results were expressed as ABSU/g (absolute unit/gram).

\section{Irisin and betatrophin measurement}

Serum irisin levels were measured using a commercially available enzyme-linked immunosorbent assay (ELISA) kit (Eastbiopharm, Hangzhou, China) and serum betatrophin concentration was determined using a commercially available human ELISA kit (USCN Life Science Inc., China) with both an intra- and an inter-assay coefficient of variation $<10 \%$. Irisin and betatrophin results were expressed as $\mu \mathrm{g} / \mathrm{mL}$ and $\mathrm{ng} / \mathrm{mL}$ respectively.

\section{Statistical analysis}

Statistical analysis was performed using SPSS 19.0 (SPSS for Windows, SPSS, Chicago). Normally distributed data were expressed as mean \pm standard deviation (SD) and non-normally distributed data were expressed as median and interquartile range. Depending on the distribution characteristics of the data parametric or non-parametric statistical tests were used. The differences among groups were analyzed using the Mann-Whitney $U$ test. Bivariate correlations were assessed using standardized Pearson coeffi- cients. Odds ratios (95\% confidence intervals) of the independent clinical parameters were calculated with univariate and multiple logistic regression models to predict GDM. A multivariate logistic regression analysis was built by performing stepwise variable selection on those variables with a univariate $P$ value $<0.25$. The $P$ values obtained of less than 0.05 was considered as statistically significant.

\section{Results}

The mean ages of the women in the GDM and control groups were $30.75 \pm 4.99$ and $28.17 \pm 5.15$ years respectively $(P=0.181)$. Clinical, metabolic and laboratory characteristics of patients in both groups are represented in Table 1 . Blood glucose and OGTT measurements were found to be elevated in GDM women. HOMA-IR of GDM patients and controls were $3.36 \pm 2.19$ and $2.07 \pm 1.38$ respectively $(P=0.001)$. A statistically significant increase in terms of IMA and IMAR was observed in GDM patients $(\mathrm{P}=0.001$ and $\mathrm{P}=$ 0.002 respectively). Serum irisin levels were 2,62 $\pm 1,20$ in GDM patients and $3.41 \pm 2.22$ in healthy pregnant women. This difference was found to be statistically significant between two groups $(P=0.038)$ (Fig. 1). Betatrophin levels were not found to be significant between study groups $(P=0.881)$.

Correlation analysis revealed a significant correlation between circulating irisin and IMAR $(P=0.012)$. No other significant correlations were found with other 


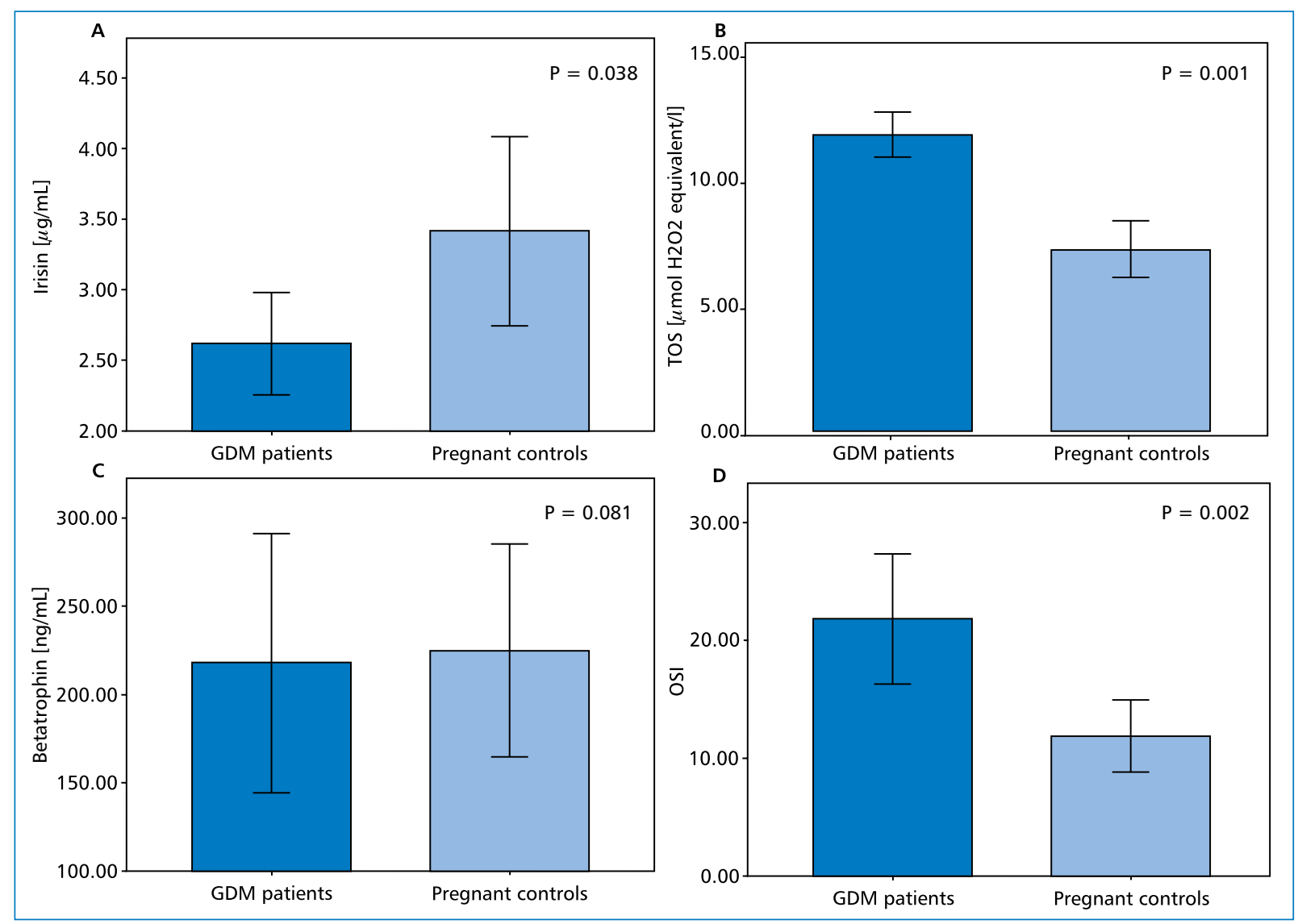

Figure 1. Box plot presentation of serum. A - irisin; B - TOS; C - betatrophin; D - OSI levels in study groups

Table 2. Correlations between serum TOS, OSI, irisin, and betatrophin with other demographic and laboratory parameters

\begin{tabular}{lccccccccc}
\hline & \multicolumn{9}{c}{ GDM patients $(\mathbf{n}=\mathbf{4 5})$} \\
\cline { 2 - 10 } & \multicolumn{2}{c}{ Betatrophin } & \multicolumn{2}{c}{ Irisin } & \multicolumn{2}{c}{ TOS } & \multicolumn{3}{c}{ OSI } \\
\cline { 2 - 10 } & $\mathbf{r}$ & $\mathbf{P}$ & $\mathbf{r}$ & $\mathbf{P}$ & $\mathbf{r}$ & $\mathbf{P}$ & & $\mathbf{r}$ & $\mathbf{P}$ \\
\hline Maternal age (years) & -0.86 & 0.572 & 0.118 & 0.442 & 0.170 & 0.345 & 0.121 & 0.501 \\
BMI at the time of OGTT & -0.195 & 0.200 & 0.079 & 0.604 & 0.156 & 0.386 & 0.094 & 0.601 \\
HOMA-IR & 0.022 & 0.886 & 0.147 & 0.335 & 0.092 & 0.299 & 0.162 & 0.368 \\
TAS & 0.013 & 0.945 & -0.144 & 0.423 & -0.117 & 0.517 & -0.882 & 0.000 \\
IMA & -0.144 & 0.346 & 0.209 & 0.168 & -0.92 & 0.610 & -0.087 & 0.629 \\
IMAR & -0.101 & 0.510 & 0.371 & 0.012 & 0.120 & 0.507 & 0.094 & 0.603 \\
OSI & -0.175 & 0.330 & 0.207 & 0.248 & 0.501 & 0.003 & & \\
TOS & -0.149 & 0.406 & 0.368 & 0.035 & & & & & \\
Irisin & 0.349 & 0.019 & & & & & & \\
\hline
\end{tabular}

study parameters in GDM patients (Table 2). A multivariable analysis revealed that TOS and OSI are significant predictors of GDM development (Table 3).

\section{Discussion}

Although the present study demonstrated that serum irisin levels were significantly lower in GDM patients, serum betatrophin levels were found to be similar in both study groups. Moreover, serum TOS levels and OSI were found to be increased in patients with GDM. Interestingly, no significant difference was observed between groups in respect to serum IMA levels and IMAR measurements.

Irisin is a recently discovered myokine that is encoded by the fibronectin type III domain-containing protein 5 (FNDC5) precursor gene. It has been sugges- 
Table 3. Univariate and multivariate logistic regression analysis of study variables for the prediction of gestational diabetes mellitus

\begin{tabular}{|c|c|c|c|c|c|c|}
\hline & \multicolumn{3}{|c|}{ Univariable analysis } & \multicolumn{3}{|c|}{ Multivariable analysis } \\
\hline & OR & $95 \% \mathrm{Cl}$ & $P$ value & OR & $95 \% \mathrm{Cl}$ & P value \\
\hline Age (years) & 1.254 & $0.824-1.688$ & 0.224 & & & \\
\hline Fasting glucose $[\mathrm{mg} / \mathrm{dL}]$ & 1.091 & $1.044-1.140$ & $<0.001$ & 1.068 & $1.010-1.129$ & 0.022 \\
\hline OGTT-1 ${ }^{\text {st }}$ hour $[\mathrm{mg} / \mathrm{dL}]$ & 1.053 & $1.031-1.075$ & $<0.001$ & 1.039 & $1.013-1.065$ & 0.002 \\
\hline OGTT-2 ${ }^{\text {nd }}$ hour $[\mathrm{mg} / \mathrm{dL}]$ & 1.058 & $1.032-1.084$ & $<0.001$ & 1.043 & $1.013-1.075$ & 0.005 \\
\hline Insulin $[\mu \mathrm{IU} / \mathrm{mL}]$ & 1.068 & $1.006-1.134$ & 0.031 & & & \\
\hline HOMA-IR (\%) & 1.534 & $1.153-2.040$ & 0.003 & & & \\
\hline Albumin [g/dL] & 0.037 & $0.004-0.305$ & 0.002 & & & \\
\hline TOS & 1.827 & $1.277-2.614$ & 0.001 & 1.762 & $1.236-2.512$ & 0.002 \\
\hline TAS & 0.798 & $0.168-3.780$ & 0.776 & & & \\
\hline OSI & 1.079 & $1.020-1.142$ & 0.008 & & & \\
\hline IMA [ABSU] & 0.742 & $0.134-2.944$ & 0.083 & & & \\
\hline IMAR $[A B S U / g]$ & 0.841 & $0.234-3.981$ & 0.591 & & & \\
\hline Betatrophin $[\mathrm{ng} / \mathrm{mL}]$ & 1.000 & $0.998-1.002$ & 0.991 & & & \\
\hline Irisin $[\mu \mathrm{g} / \mathrm{mL}]$ & 0.992 & $0.892-1.102$ & 0.878 & & & \\
\hline
\end{tabular}

ted to be involved in mediating the favorable effects of exercise on the metabolism and its elevated levels induce browning of subcutaneous adipocytes and thermogenesis [21]. Moreover, accumulating evidence suggests that a decrease in circulating irisin levels may be linked with the development of impaired glucose metabolism and IR. Due to the vital impacts of irisin on body metabolism, several studies have been conducted to investigate the association between circulating irisin and metabolic disorders. In most of these studies, the variation of irisin levels was found to be affected by insulin metabolism. However, an association between irisin and IR, in particular during pregnancy, seems still controversial. In a study by Kuzmicki et al. [7] 130 women with GDM and $140 \mathrm{BMI}-$ matched pregnant women with normal glucose tolerance were investigated. Mean irisin levels were found to be lower in patients with GDM compared to healthy pregnant women. Similarly, Yuksel et al. [6] reported that maternal serum irisin levels of patients with GDM were significantly lower compared with non-GDM controls. Contrary to these findings Ebert et al. [22] and Sancak et al. [23] demonstrated no significant difference in GDM patients. Therefore, the finding of lower levels of circulating irisin in the present study is noteworthy. Unfortunately, we didn't detect any correlation in GDM patients with respect to irisin and IR (measured as HOMA-IR). These discrepancies may be due to differences in the clinical characteristics of the subjects studied.

Betatrophin is a newly identified liver and adipose tissue-derived hormone with implications in the regulation of lipid metabolism, beta-cell replication and glucose homeostasis [24]. The scientific evidence linking betatrophin with obesity, peripheral artery disease and DM is enlarging, but data exploring the association between betatrophin status and GDM are still controversial $[10,25,26]$. In this regard, some studies reported higher betatrophin concentrations in GDM patients, while some studies showed the contrary [24, 27-30]. Wawrusiewicz-Kurylonek et al. [28] showed that circulating betatrophin levels are dramatically increased in pregnancy and are significantly elevated in GDM patients compared with healthy pregnants. Similarly, Pan et al. [31] found that betatrophin concentration was remarkably higher in patients with than without GDM. However, Huang et al. [27] demonstrated no significant difference between GDM and healthy pregnants with respect to circulating betatrophin levels. We also observed no significant difference between groups in terms of serum betatrophin levels.

Five oxidative stress parameters were analyzed in this study. But only TOS and OSI levels were found to be increased in GDM patients. Increased TOS levels and reduction in total TAS levels have been implicated in several disease states, such as DM, cancer and heart diseases [32-34]. But there are only a few studies in literature investigated the levels of TOS and TAS in GDM patients. Zhou et al. [35] demonstrated that total TOS and TAS levels were increased in GDM suggesting that increased OS and abnormalities in lipoproteins may be associated with the metabolic alterations in GDM. Usluoğulları et al. [36] not only reported elevated TOS and OSI levels but also decreased irisin levels in GDM patients. As being the first study to investigate the relation between serum 
irisin levels and TOS, TAS, and OSI in patients with GDM, the authors demonstrated a strong correlation between TOS and irisin levels suggesting irisin as an OS marker and a metabolic protective hormone.

IMA is an "N-terminal modified" albumin which is generated immediately following ischemic conditions and IMAR is the percentage ratio of IMA to albumin that is used to eliminate the effect of reduced albumin concentrations. Studies showed that in certain conditions like cirrhosis and preeclampsia IMAR represents OS status more effectively $[37,38]$. IMA was originally evaluated in patients with myocardial ischemia and later it has been identified to be helpful for evaluating patients with distinct disease conditions including type 2 DM, coronary ischemia, coronary bypass surgery, advanced cancer, systemic sclerosis, pulmonary embolism, liver cirrhosis, and metabolic syndrome [39-41]. Although, elevated IMA levels due to the physiologic OS state of pregnancy have been demonstrated previously, Ma et al. [2] was the first that evaluated IMA levels in GDM patients. The authors showed that IMA levels were elevated in GDM patients with a positive correlation with serum glucose levels. Furthermore, glycemic levels in GDM were correlated with concentrations of lipid peroxides and increased protein oxidation. In the present study, we did not find any significant difference between study groups in terms of IMA and IMAR. More importantly, there were no correlations between IMA and other maternal characteristics. This result can be interpreted as IMA was not influenced from other metabolic characteristics including IR and glucose metabolism.

A limitation of our study is the limited number of study participants. However, we must note that despite the relatively small sample sizes, the validity of our results is strengthened by the close matching of study groups including age, gestational weeks, gravidity and $\mathrm{BMI}$, thus negating these parameters as confounders. Another limitation is the variety of physiological factors that can affect the levels of IMA in the body.

In conclusion, the present study confirmed lower levels of irisin and increased TOS and OSI as a marker of ongoing OS in GDM patients. However, the clinical significance of unaltered betatrophin levels demonstrated in this study remained unclear. Therefore, we believe that future large-scale prospective follow-up studies are essential for the standardization of irisin, betatrophin and OS measurements and also to clarify contradictory results.

\section{Conflict of interest}

The authors have no potential conflicts of interest or funding sources to declare.

\section{REFERENCES}

1. Al-Ghazali MJ, Ali HA, Al-Rufaie MM. Serum irisin levels as a potential marker for diagnosis of gestational diabetes mellitus. Acta Biomed. 2020; 91(1): 56-63, doi: 10.23750/abm.v91i1.7675, indexed in Pubmed: 32191655.

2. Ma Sg, Yu Wn, Jin Y, et al. Evaluation of serum ischemia-modified albumin levels in pregnant women with and without gestational diabetes mellitus. Gynecol Endocrinol. 2012; 28(11): 837-840, doi: 10.3109/09513590.2012.683069, indexed in Pubmed: 22571721.

3. Li YT, Kuo TC, Wang PH. Low serum level of irisin and gestational diabetes mellitus. Taiwan J Obstet Gynecol. 2019; 58(4): 443-444, doi: 10.1016/j.tjog.2019.05.001, indexed in Pubmed: 31307729.

4. Khambule L, George JA. The role of inflammation in the development of GDM and the use of markers of inflammation in GDM screening. Adv Exp Med Biol. 2019; 1134: 217-242, doi: 10.1007/978-3-030-12668-1_12, indexed in Pubmed: 30919340.

5. Wang $\mathrm{P}, \mathrm{Ma} \mathrm{HH}, \mathrm{Hou} X Z$, et al. Reduced plasma level of irisin in first trimester as a risk factor for the development of gestational diabetes mellitus. Diabetes Res Clin Pract. 2018; 142: 130-138, doi: 10.1016/j.diabres.2018.05.038, indexed in Pubmed: 29852234.

6. Yuksel MA, Oncul M, Tuten A, et al. Maternal serum and fetal cord blood irisin levels in gestational diabetes mellitus. Diabetes Res Clin Pract. 2014; 104(1): 171-175, doi: 10.1016/j.diabres.2013.12.025, indexed in Pubmed: 24447809.

7. Kuzmicki M, Telejko B, Lipinska D, et al. Serum irisin concentration in women with gestational diabetes. Gynecol Endocrinol. 2014; 30(9): 636-639, doi: 10.3109/09513590.2014.920006, indexed in Pubmed: 24850254

8. Ebert T, Kralisch S, Wurst U, et al. Betatrophin levels are increased in women with gestational diabetes mellitus compared to healthy pregnant controls. Eur J Endocrinol. 2015; 173(1): 1-7, doi: 10.1530/EJE-14-0815, indexed in Pubmed: 25850828.

9. Niki $\mathrm{H}$, Kishimoto $\mathrm{Y}$, Ibe $\mathrm{S}$, et al. Associations between plasma betatrophin levels and coronary and peripheral artery disease. J Atheroscler Thromb. 2019; 26(6): 573-581, doi: 10.5551/ jat.46508, indexed in Pubmed: 30518729.

10. Ye J, Qin Yu, Wang D, et al. The Relationship between circulating ANGPTL8/betatrophin concentrations and adult obesity: a meta-analysis. Dis Markers. 2019; 2019: 5096860, doi: 10.1155/2019/5096860, indexed in Pubmed: 31772689.

11. Battal F, Türkön $H$, Aylanç $N$, et al. Investigation of blood betatrophin levels in obese children with non-alcoholic fatty liver disease. Pediatr Gastroenterol Hepatol Nutr. 2018; 21(2): 111-117, doi: 10.5223/pghn.2018.21.2.111, indexed in Pubmed: 29713608.

12. Li S, Liu D, Li L, et al. Circulating betatrophin in patients with type 2 diabetes: a meta-analysis. J Diabetes Res. 2016; 2016: 6194750, doi: 10.1155/2016/6194750, indexed in Pubmed: 26697500.

13. Li H, Yin Q, Li N, et al. Plasma markers of oxidative stress in patients with gestational diabetes mellitus in the second and third trimester. Obstet Gynecol Int. 2016; 2016: 3865454, doi: 10.1155/2016/3865454, indexed in Pubmed: 27803713.

14. Usluoğullari B, Usluogullari CA, Balkan F, et al. Role of serum levels of irisin and oxidative stress markers in pregnant women with and without gestational diabetes. Gynecol Endocrinol. 2017; 33(5): 405-407, doi: 10.1080/09513590.2017.1284789, indexed in Pubmed: 28277125.

15. Mohsen L, Akmal DM, Ghonaim EK, et al. Role of mean platelet volume and ischemia modified albumin in evaluation of oxidative stress and its association with postnatal complications in infants of diabetic mothers. J Matern Fetal Neonatal Med. 2018; 31(14): 1819-1823, doi: 10.1080/14767058.2017.1330329, indexed in Pubmed: 28502205.

16. Ozler S, Oztas E, Uygur D, et al. The value of total antioxidant status and serum tumor necrosis factor- $\alpha$ levels at 24-28 weeks of gestation in the prediction of optimal treatment protocol in gestational diabetes mellitus. Exp Clin Endocrinol Diabetes. 2019; 127(7): 485-491, doi: 10.1055/s-0035-1554623, indexed in Pubmed: 26011173. 
17. Metzger BE, Gabbe SG, Persson B, et al. International Association of Diabetes and Pregnancy Study Groups Consensus Panel. International association of diabetes and pregnancy study groups recommendations on the diagnosis and classification of hyperglycemia in pregnancy. Diabetes Care. 2010; 33(3): 676-682, doi: 10.2337/dc09-1848, indexed in Pubmed: 20190296.

18. Matthews DR, Hosker JP, Rudenski AS, et al. Homeostasis model assessment: insulin resistance and beta-cell function from fasting plasma glucose and insulin concentrations in man. Diabetologia. 1985; 28(7): 412-419, doi: 10.1007/BF00280883, indexed in Pubmed: 3899825.

19. Jansen EH, Ruskovska T. Comparative analysis of serum (anti) oxidative status parameters in healthy persons. Int J Mol Sci. 2013; 14(3): 6106-6115, doi: 10.3390/ijms14036106, indexed in Pubmed: 23507749.

20. Bar-Or D, Lau E, Winkler JV. A novel assay for cobalt-albumin binding and its potential as a marker for myocardial ischemia a preliminary report. J Emerg Med. 2000; 19(4): 311-315, doi: 10.1016/s0736-4679(00)00255-9, indexed in Pubmed: 11074321.

21. Pérez-Sotelo D, Roca-Rivada A, Baamonde I, et al. Lack of adipocyte-Fndc5/irisin expression and secretion reduces thermogenesis and enhances adipogenesis. Sci Rep. 2017; 7(1): 16289, doi: 10.1038/s41598-017-16602-z, indexed in Pubmed: 29176631.

22. Ebert T, Stepan H, Schrey S, et al. Serum levels of irisin in gestational diabetes mellitus during pregnancy and after delivery. Cytokine. 2014; 65(2): 153-158, doi: 10.1016/j.cyto.2013.11.009, indexed in Pubmed: 24355429.

23. Sancak S, Aydin H, Sargin M, et al. Serum irisin level increases throughout the gestational period and it does not play role in development of gestational diabetes mellitus. Acta Endocrinol (Buchar). 2017; 13(4): 393-399.

24. Kong FJ, Ma LL, Li G, et al. PLOS ONE Staff Correction: Circulating betatrophin levels and gestational diabetes mellitus: a systematic review and meta-analysis. PLoS One. 2017; 12(2): e0172449, doi: 10.1371/journal.pone.0172449, indexed in Pubmed: 28196120.

25. Niki H, Kishimoto $\mathrm{Y}$, Ibe $\mathrm{S}$, et al. Associations between plasma betatrophin levels and coronary and peripheral artery disease. J Atheroscler Thromb. 2019; 26(6): 573-581, doi: 10.5551/ jat.46508, indexed in Pubmed: 30518729.

26. Battal F, Türkön $H$, Aylanç N, et al. Investigation of blood betatrophin levels in obese children with non-alcoholic fatty liver disease. Pediatr Gastroenterol Hepatol Nutr. 2018; 21(2): 111-117, doi: 10.5223/pghn.2018.21.2.111, indexed in Pubmed: 29713608.

27. Huang $Y$, Fang $C, M a Z$, et al. Betatrophin levels were increased in pregnant women with or without gestational diabetes mellitus and associated with beta cell function. Rev Bras Ginecol Obstet. 2016; 38(6): 287-292, doi: 10.1055/s-0036-1584566, indexed in Pubmed: 27399923.

28. Wawrusiewicz-Kurylonek N, Telejko B, Kuzmicki M, et al. Increased maternal and cord blood betatrophin in gestational diabetes. PLoS One. 2015; 10(6): e0131171, doi: 10.1371/journal.pone.0131171, indexed in Pubmed: 26115519.

29. Erol O, Ellidağ HY, Ayık H, et al. Evaluation of circulating betatrophin levels in gestational diabetes mellitus. Gynecol Endocrinol. 2015; 31(8): 652-656, doi: 10.3109/09513590.2015.1056142, indexed in Pubmed: 26291796.
30. Xie X, Gao H, Wu S, et al. Increased cord blood betatrophin levels in the offspring of mothers with gestational diabetes. PLoS One. 2016; 11(5): e0155646, doi: 10.1371/journal.pone.0155646, indexed in Pubmed: 27196053.

31. Pan R, Zhang H, Yu S, et al. Betatrophin for diagnosis and prognosis of mothers with gestational diabetes mellitus. J Int Med Res. 2019; 47(2): 710-717, doi: 10.1177/0300060518808683, indexed in Pubmed: 30392425.

32. Eraldemir FC, Üren N, Kum T, et al. Association of serum paraoxonase 1 activities, polymorphisms and oxidative stress in breast cancer patients with type 2 diabetes mellitus. J Med Biochem. 2019; 38(3): 368-375, doi: 10.2478/jomb-2018-0043, indexed in Pubmed: 31156348.

33. Xiang M, Feng J, Geng L, et al. Sera total oxidant/antioxidant status in lung cancer patients. Medicine (Baltimore). 2019; 98(37): e17179, doi: 10.1097/MD.0000000000017179, indexed in Pubmed: 31517874.

34. Bhat MA, Gandhi G. Elevated oxidative DNA damage in patients with coronary artery disease and its association with oxidative stress biomarkers. Acta Cardiol. 2019; 74(2): 153-160. doi: 10.1080/00015385.2018.1475093, indexed in Pubmed: 29914299.

35. Zhou Mi, Liu XH, Liu QQ, et al. Lactonase activity, status, and genetic variations of paraoxonase 1 in women with gestational diabetes mellitus. J Diabetes Res. 2020; 2020: 3483427, doi: 10.1155/2020/3483427, indexed in Pubmed: 32090118.

36. Usluoğullari B, Usluogullari CA, Balkan $F$, et al. Role of serum levels of irisin and oxidative stress markers in pregnant women with and without gestational diabetes. Gynecol Endocrinol. 2017; 33(5): 405-407, doi: 10.1080/09513590.2017.1284789, indexed in Pubmed: 28277125.

37. Chen CY, Tsai WL, Lin PJ, et al. The value of serum ischemia-modified albumin for assessing liver function in patients with chronic liver disease. Clin Chem Lab Med. 2011; 49(11): 1817-1821, doi: 10.1515/CCLM.2011.675, indexed in Pubmed: 21851314

38. D'souza JMP, Pai VR, Harish S, et al. IMA and IMAR in serum and saliva of preeclampsia--a preliminary study. Hypertens Pregnancy. 2014; 33(4): 440-448, doi: 10.3109/10641955.2014.931418, indexed in Pubmed: 25019475.

39. Beyazit F, Yilmaz N, Balci O, et al. Evaluation of oxidative stress in women with polycystic ovarian syndrome as represented by serum ischemia modified albumin and its correlation with testosterone and insulin resistance. Intern Med. 2016; 55(17): 2359-2364, doi: 10.2169/internalmedicine.55.6265, indexed in Pubmed: 27580534.

40. Duarte MM, Rocha JBT, Moresco RN, et al. Association between ischemia-modified albumin, lipids and inflammation biomarkers in patients with hypercholesterolemia. Clin Biochem. 2009; 42(78): 666-671, doi: 10.1016/j.clinbiochem.2009.01.010, indexed in Pubmed: 19318029.

41. Bhakthavatsala Reddy C, Cyriac C, Desle HB. Role of "Ischemia Modified Albumin" (IMA) in acute coronary syndromes. Indian Heart J. 2014; 66(6): 656-662, doi: 10.1016/j.ihj.2014.12.005, indexed in Pubmed: 25634401. 